\title{
Cell surface engineering and application in cell delivery to heart diseases
}

\author{
Daniel Y. Lee, Byung-Hyun Cha, Minjin Jung, Angela S. Kim, David A. Bull and Young-Wook Won*
}

\begin{abstract}
Cell-based therapy has expanded its influence in cancer immunotherapy, regenerative medicine, and tissue engineering. Due to their secretory functions, differentiation capabilities, specific homing effects through chemotaxis, distinctive therapeutic potentials, and ex vivo expandability, cells have become an attractive reagent for advanced therapeutic strategies. Therefore, the ability to modify cells and manipulate their functions according to intended therapeutic designs has been the central scientific interest in the field of biomedical research. Many innovative methods have been developed with genetic modification of cells being the most advanced cell surface engineering technique. Although genetic modification is a powerful tool, it has a limited applicability due to the permanent modifications made on cells. Alternatively, many endeavors have been made to develop surface engineering techniques that can circumvent the limitations of genetic modification. In this review, current methods of non-genetic cell surface modification, including chemical conjugations, polymeric encapsulation, hydrophobic insertion, enzymatic and metabolic addition, will be introduced. Moreover, cell surface engineering plausible for cardiac remodeling and the future prospective will be discussed at the end.
\end{abstract}

Keywords: Cell surface engineering, cell modification, mesenchymal stem cells, cell therapy, cardiac diseases, cardiac repair

\section{Background}

Cell surface engineering to provide new characteristics and functions to cells has drawn continuous interest from researchers in biomedical science as cell therapy has emerged as a prominent therapeutic strategy equivalent and complementary to the conventional therapeutic approaches. Research endeavors over the past several decades have identified various types of cells as suitable living drugs and versatile drug carriers. In particular, stem cells, including mesenchymal stem cells (MSCs), hematopoietic stem cells (HSCs), and induced pluripotent stem cells (iPSCs), and immune cells, such as T-cells and Natural Killer (NK) cells, have been favored candidates for regenerative medicine and cell-based cancer immunotherapy, respectively. Both bone marrow-derived and adipose-derived MSCs readily isolated from the body are able to release cytokines and growth factors that can be utilized towards wound healing, treating cardiovascular diseases, and correcting

\footnotetext{
* Correspondence: youngwookwon@email.arizona.edu Division of Cardio-Thoracic Surgery, Department of Surgery, University of Arizona College of Medicine, Room 4302D, 1501 N Campbell Ave, Tucson, Arizona 85724, USA
}

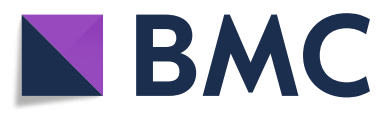

(c) The Author(s). 2018 Open Access This article is distributed under the terms of the Creative Commons Attribution 4.0 International License (http://creativecommons.org/licenses/by/4.0/), which permits unrestricted use, distribution, and reproduction in any medium, provided you give appropriate credit to the original author(s) and the source, provide a link to the Creative Commons license, and indicate if changes were made. The Creative Commons Public Domain Dedication waiver (http://creativecommons.org/publicdomain/zero/1.0/) applies to the data made available in this article, unless otherwise stated.

neurological disorders [1-7]. Adoptive transfer of ex vivo cultured and activated immune cells isolated from cancer patients has shown refreshing clinical results $[8,9]$. Unfortunately, these breakthrough discoveries in both regenerative medicine and cancer immunotherapy using cells as therapeutic reagents soon faced a common problem: the inability to control cellular functions to maximize the therapeutic benefits. MSCs directly injected into the myocardium showed low retention rate with only $0.44 \%$ of the transplanted MSCs remaining in the myocardium after 4 days of administration [10]. Moreover, systemic injection of MSCs on rat myocardial infarction (MI) models revealed less than $1 \%$ accumulation of MSCs in the ischemic myocardium [11]. To overcome the low retention rates and enhance the target homing effect, MSCs were genetically engineered to overexpress $\mathrm{CXC}$ chemokine receptor 4 (CXCR4), a receptor for stromal-derived factor-1 (SDF-1) expressed in injured myocardium [12]. The resulting genetically modified MSCs showed enhanced target homing effect and greater retention rate in the ischemic myocardium after the intravenous delivery. The developmental story of cell-based cancer immunotherapy is not so different from 
MSCs in regenerative medicine. Although the efficacy of adoptive transfer of tumor infiltrating lymphocytes (TILs) was examined over several decades, genetically engineered $\mathrm{T}$ cells expressing chimeric antigen receptors (CARs) rapidly replaced the application of TILs due to their high specificity, non-MHC-restricted recognition of tumor antigen, superior potency, and improved in vivo persistency $[9,13,14]$.

Early attempts to control the cellular interactions and reprogramming the cellular functions focused on the $e x$ vivo preconditioning $[15,16]$. In this method, multiple stimuli, including pharmacological agents, cytokines, stimulatory ligands, and/or microenvironmental preconditioning, are challenged to the cells of interest in order to achieve enhanced cell survival, differentiation, paracrine effects, specificity, potency, and target homing effect. For instance, hypoxic conditioning increased the expression of pro-survival and pro-angiogenic factors on MSCs and improved their potential to repair the injured myocardium [17, 18]. Many ex vivo immune cell expansion and activation protocols also require addition of cytokines, such as interleukin (IL)-2, IL-12, IL-15, IL-18, and IL-2, to the culture media $[15,19]$. Although preconditioning methods improved the in vivo cell retention and survival, they only allowed minimal gain of control to manipulate the cellular functions that is necessary to redirect cells for therapeutic purposes. As cell therapy continues to evolve, preconditioning methods have been integrated as essential protocols for the growth and maintenance of cells cultured in ex vivo conditions, and many creative methods have been developed to improve the therapeutic feasibility and effectiveness of cells.

Genetic engineering, currently the state-of-the-art modification techniques, has opened up new avenues to tailor preexisting cells to acquire specific therapeutic functions. The most celebrated example is the aforementioned CAR-T cells. Recently, the United States Food and Drug Administration (FDA) approved two CAR-T cells, Kymriah $^{\text {Tw }}$ and Yescarta ${ }^{\text {Tw }}$, for the treatment of B cell precursor acute lymphoblastic leukemia (BCP-ALL) and large B cell lymphoma [20]. Both CAR-T cells are engineered to express CARs specific for CD19 expressed on normal and malignant B lineage cells. Genetic engineering also extends its application to modify MSCs by overexpressing receptors and proteins for regenerative medicine: CXCR4 to take advantage of SDF-1 chemotaxis; fibroblast growth factor-2 (FGF2) for improved viability after transplantation into injured myocardium; heme oxygenase-1 (HO-1) to improve cell survival, organ recovery, and function in injured heart; and vascular endothelial growth factor (VEGF) for angiogenesis and inhibition of progression of left ventricular hypertrophy [21, 22]. Undoubtedly, genetic engineering is a powerful tool to control the cellular function of cells; however, it has several drawbacks requiring profound consideration for incorporation into the therapeutic designs. The major drawback is the use of viral vectors to deliver therapeutic genes into the cells of interest [21, 23-26]. Viral vectors have higher risk of genetic integration that may lead to tumorigenesis and trigger immunogenic response [27]. Additional features introduced to cells through viral genetic engineering are permanent and irreversible, exacerbating the safety risk in clinical settings $[28,29]$. Non-viral gene carriers alleviate the safety concerns; however, they show rather low transfection efficiency compared to viral vectors [30]. Because the success of genetic engineering heavily depends on the transduction/transfection efficiency, the resulting modified cells may show inconsistent and unpredictable therapeutic efficacy. This is because genetic engineering is not applicable to all types of cells, especially stem cells and slowly dividing cells.

Alternative to genetic engineering, non-genetic cell surface engineering techniques, such as covalent conjugation [31-34], electrostatic interactions [35-37], hydrophobic insertion [38-43], offer more transient and reversible modifications to control cellular functions. Instead of manipulating cells at the gene and protein level, these techniques modify the cell using the characteristics of lipids, proteins, and glycans present in the cell membrane $[5,29,44,45]$. Because those are essential components for cells, non-genetic surface engineering techniques can potentially be applied to a broad range of cells from different origins. Through non-genetic cell surface engineering, biomaterials including proteins, surface receptors, antibodies, peptides, genetic materials, and protective polymers, have been used to endow specific functions to cells [31, 33, 34, 42, 44, 46-48]. Research areas that have benefitted from these cell surface modifications include (1) investigation of adding new functions, (2) reducing graft rejection for transplantation by masking the surface antigens, (3) creation of heterogeneous cluster of cells by cell-to-cell attachment, (4) enhancing immune effector functions, and (5) programing cell-to-cell interactions.

Ideal cell surface engineering methods should provide control over the fate and function of the modified cells without interfering with cell survival, proliferation, and cellular activities. Therefore, this review attempts to provide a concise guide on cell surface engineering techniques that meet the purpose of modifying the cell surface properties. The first section summarizes each type of non-genetic cell surface engineering technique with application on different cell types. In the following section, challenges and considerations of engineering the surface of living cells are discussed. Finally, example of cell surface engineering technique is presented as a promising method to redirect MSCs for cardiac diseases. 


\section{Non-genetic Surface Engineering Covalent Conjugation}

Covalent conjugation chemically, metabolically, or enzymatically attaches bioactive substances to the cell membrane [31, 33, 34, 48-51]. Chemical conjugation is the most straightforward method that takes advantage of surface-exposed functional groups on the membrane proteins as grafting points. Currently, $N$-hydroxyl-succinimidyl ester (NHS) groups [31, 33, 34, 48], maleimide [51], and pyridyldithiol $[52,53]$ are the most frequently used chemical cross-linkers (Fig. 1). The use of NHS-activated esters modifies exposed amine groups on the surface of bioactive molecules. Maleimide conjugated biomolecules can be selectively attached to surface-exposed thiol group, generating a non-cleavable thio-ether bond. In case degradable conjugation is desired, pyridyldithiol modified biomolecules can be attached to free thiols on the surface to create reducible disulfide bonds. The key advantage of chemical conjugation is the broad applicability. Biomaterials functionalized with cross-linkers can be used to modify variety of cells. Unlike the random modification through chemical conjugation, metabolic and enzymatic conjugation methods provide more selective attachment of biomaterials. Saxon et al. and Prescher et al. reported the use of sophisticated metabolic surface modification that takes advantage of unnatural sialic acid biosynthesis $[49,50]$. Human cells undergo unnatural sialic acid biosynthesis when exposed to unnatural sugar $N$ - $\alpha$-azidoacetylmannosamine (ManNAz), an analog of the native sugar $N$-acetylmannosamine (Fig. 1). This process incorporates $N$ - $\alpha$-azidoacetyl sialic acid (SiaNAz), a metabolite of Man$\mathrm{NAz}$, to the membrane glycoconjugates. The added azide groups further provide attachment points for biomaterials through Staudinger ligation [49, 50] or click-chemistry $[54,55]$. Similar to metabolic conjugation, enzymatic conjugation also provides covalent attachment of biomaterials on a designated spot on the cell surface. As reported by Swee et al., transpeptidase sortase A from Staphylococcus aureus efficiently conjugates peptides or proteins with LPETG-motif to the N-terminal glycine exposed on the surface of different types of cells (Fig. 1) [56]. Although conjugated biomaterials gradually disappear over time, modifications installed through covalent conjugation are stable compare to other non-genetic surface engineering methods [33, 34, 40]. Moreover, the degree of modification is difficult to control with covalent conjugation, and higher degree of modification using bioactive molecules, both small or large, may cause significant physiological alterations, such as reduction of membrane mobility and diffusion kinetics to the modified cells [38, 44, 57].

\section{Electrostatic Interaction}

Electrostatic interactions modify the cell surface by establishing self-assembled structures between the negatively charged cell surface and cationic polymers (Fig. 1). Cells initially modified with cationic polymers can be engineered again via a layer-by-layer technique by sequentially applying anionic and cationic polymers [35, 37, 58-60]. Because modified cells encapsulated by multiple polymeric layers can reduce molecular recognition, the electrostatic layer-by-layer approach has been often investigated in the cell transplantation research [37, 59]. Many cationic/anionic polymers and poly electrolytes, such as poly-L-lysine (PLL), poly(styrene) sulfate (PSS), poly(allylamine hydrochloride) (PAH), poly(diallydimethylammonium) chloride (PDADMAC or PDDA), poly(ethyleneimine) (PEI), polyphosphoric acid (PPP), and poly(acrylic acid) (PAA), and hyaluronic acid (HA) have been used to generate multiple layers on the cell membrane [35, 37, 58-61]. Thickness of the polymer layer can be controlled by changing the number of layers and the new surface properties of the modified cells rely on the polymer characteristics of the outermost layer. However, it should be noted that high charge density of cationic polymers significantly reduces the viability of modified cells $[58,62,63]$. To improve the cell viability after the surface modification, PLL-graft-poly(ethylene glycol) (PLL-g-PEG) can be introduced to coat the surface cells $[59,64]$. Surface modification of PLL- $g$-PEG was further developed to incorporate functional groups, such as biotin, hydrazide, and azide, to capture streptavidin, aldehyde, and cyclooctyne [64]. The main advantage of surface engineering through electrostatic interaction is that cells are protected from the sheer stress and immune response by the non-invasive encapsulation. Biocompatibility of cationic polymers, however, should be resolved in order to be used in cell therapy.

\section{Hydrophobic insertion}

Amphiphilic polymers polymerized with long alkyl chains, such as phospholipid-conjugated PEGs and poly(vinyl alcohol) (PVA), provide noninvasive modifications of the cell surface through hydrophobic interaction (Fig. 1). Similarly, a large number of different cell types have been modified via hydrophobic interaction with lipid-conjugated biomaterials for specific function [38-43, 57, 65-70]. Most lipophilic membrane dyes currently available in the market, such as Dil, DiD, DiR, and DiO, are developed upon cell surface modification through hydrophobic interaction. Interaction of lipid-conjugated PEGs with lipid bilayers was examined by Yamamoto et al. using surface plasmon resonance (SPR) spectroscopy [71]. Lipids with different lengths of alkyl chains-1,2-dimyristoyl-sn-glycerol-3-phosphatidylethanolamine (DMPE, 14 carbons), 1,2-dipalmitoyl-sn-glycerol-3-phosphatidylethanolamine (DPPE, 16 carbons), and 1,2-distearoyl-sn-glycerol-3-phosphatidylethanolamine (DSPE, 18 carbons) - were conjugated with PEG (5 kDa) and applied onto the lipid bilayer. Out of all lipid-PEG conjugates, DMPE showed the most rapid 


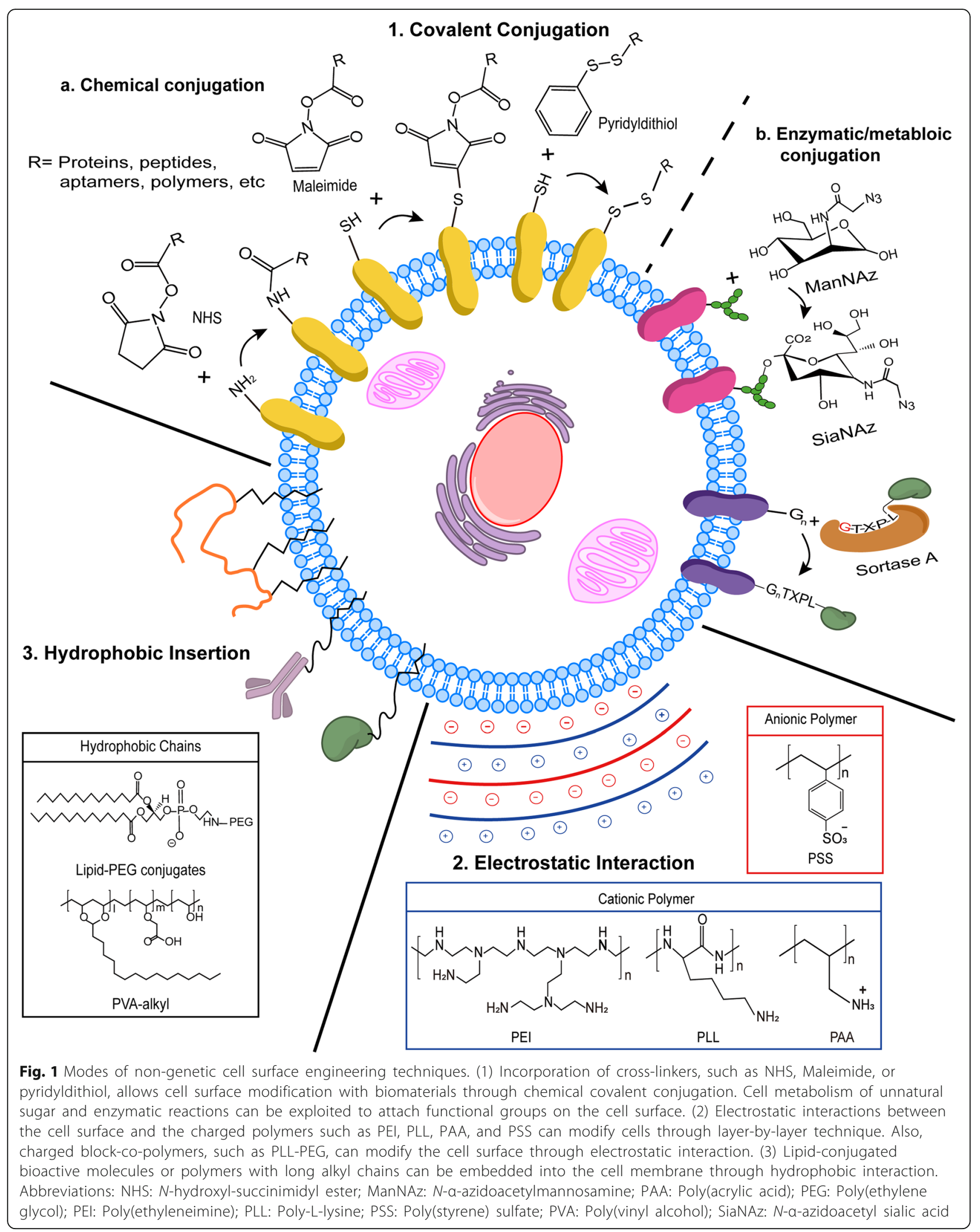


incorporation to the membrane. Insertion of DPPE showed concentration-dependent behavior; however, incorporation of DSPE was only observed at high concentration. Dissociation of DMPE was more rapid compared to DPPE when modified lipid bilayer was washed with PBS. No dissociation was observed once DSPE was incorporated into the membrane. Thus, it was noted that longer hydrophobic chains reduce the incorporation rate and the dissociation rate of lipid molecules [71]. Interestingly, fluorescence of FITC-labeled lipid-PEGs was recovered in a few minutes in fluorescent recovery after photobleaching (FRAP) assay [71]. This observation indicates that lipid-PEGs embedded in the lipid bilayer were able to diffuse laterally within the lipid bilayer. Unlike covalent conjugation and electrostatic interaction, surface modification with hydrophobic insertion allows membrane-anchored bioactive molecules to participate in the dynamic movement of cell membrane. Most importantly, cells modified with lipid-conjugated biomaterials showed negligible toxicity, and the modified cells resumed normal cellular activities [65-67]. Instead of preparing the lipid-conjugatedmolecules, modification of cell surface can be achieved by liposomal fusion strategy [72]. Because liposomes are vesicles composed of lipids and lipid-conjugated molecules, large sections of the liposomes containing specialized lipids can be incorporated into the membrane without causing severe toxicity [72-75]. Fate of the lipid-conjugated bioactive molecules has not been fully understood, and the exclusion pathway requires further investigation; however, the endocytosis of membrane-anchored lipid-conjugated biomaterials has not been observed [76]. Lipid-conjugated biomolecules are believed to be released from the cells to the surroundings due to equilibrium differences [40]. Although molecules of interest must be hydrophobized by lipid or alkyl chain conjugation and the retention time on the surface is variable, hydrophobic insertion is an attractive surface engineering technology that offers rapid and nontoxic surface modification to virtually any type of cell.

\section{Challenges and considerations of engineering the surface of living cells \\ Cell membrane dynamics}

Cell membrane is in a dynamic state. It is subjected to undergo constant remodeling where most of its components-lipids and membrane proteins-are internalized, degraded, recycled, and replaced [77, 78]. The rate of these processes is highly dependent on the type of lipids and proteins and varies widely from hours to weeks [79]. Cell membrane lipids and proteins are routinely internalized through endocytosis, pinocytosis, and phagocytosis. Due to their size, type, and property, biomaterials that are chemically conjugated, electrostatically adsorbed, or hydrophobically embedded on the membrane, may internalize mostly through endocytosis [80]. The process of endocytosis is initiated as complementary ligands bind to surface receptors or as bioactive substances are absorbed on the cell membrane [81-83]. These events trigger invaginations of small areas containing the receptors and affected regions of cell membrane. Subsequently, the invaginated pockets are closed, and newly formed vesicles are transported to the intracellular compartments. During endocytosis, any molecules and materials on the invaginated cell membrane and in the proximal media will be taken up by the cells, resulting in the loss of desired functions installed via surface engineering. Therefore, surface engineering methods should consider cell membrane dynamics in order to improve the surface residence time of the desired biomaterials for prolonged therapeutic effects.

\section{In vivo system}

Unlike the in vitro experimental settings, in vivo environment is an integrated system of many complex mechanical and biochemical interactions. Transplanted or adoptively transferred surface-engineered therapeutic cells are exposed to sheer stress and hemodynamic forces that can strip off the installed surface modification [84]. Migration in the circulation and endothelial transmigration in the tissues, as demonstrated by leukocytes and stem cells, require extensive reshaping of the cell membrane $[85,86]$. In the spleen, circulating cells are forced to enter the compact network of sinusoidal capillaries to eliminate damaged and aged cells [87]. In order to compensate for the mechanical stress from the in vivo environment, surface-engineered cells must display unaltered membrane flexibility and elasticity. Surface-engineered cells in blood circulation are also exposed to coagulation factors, the complement immune system, and inflammation mediators that drastically reduce duration of therapeutic effects [88, 89]. Macrophages and monocytes of innate immune defense system are often stimulated in response to the bioactive substances on surface-modified cells and subsequently eliminate them from the body by phagocytosis [90]. Immunogenic biomaterials, such as proteins synthesized from bacterial host and antibodies isolated from animals, are opsonized by neutralizing antibodies and are cleared by the innate immune system and complement activation [91-94]. Thus, cell surface modification, regardless of the methods employed, must not sacrifice the membrane flexibility and elasticity but rather provide new functionality in addition to the protection against mechanical and biological challenges for clinical applications. 


\section{Clinical translation}

For clinical translation, surface-engineered cells must satisfy several fundamental principles of biocompatibility. Because cells are the most critical component of cell therapy, any modifications applied to the cell surface should not have detrimental effects on cell viability. At any stage of preparation, cell viability should be maintained by changes in $\mathrm{pH}$, osmolality, temperature, pressure, degree of agitation, and exposure to organic solvent [84]. Surface modification should not become a physical barrier that blocks diffusion of necessary nutrients. This is particularity important for islet cell transplantation, where surface-modified islet cells secrete insulin in response to glucose levels [39, 66, 95]. Unless the purpose for surface engineering is to mask the surface antigens during transplantation or adoptive transfer of immune cells-for the sake of reducing the occurrence of graft-versus-host disease (GVHD) - surface proteins and receptors should be exposed on the surface without hindrance to bind growth factors and ligands to signal cell survival, proliferation, and activation. Moreover, surface engineered biomolecules should not reduce the membrane flexibility and elasticity, which are the essential properties of cell membrane that allows cell adhesion, migration, and signaling [96-99]. Lastly, the cost of surface engineering cells for therapeutic purposes must be affordable. Genetic engineered cells, such as CAR-T cells, can be finely tuned to provide personalized cell therapy for many cancers and diseases; however, the cost of treatment is extremely expensive, estimated at $\$ 25,000$ per treatment [100]. Genetically engineered stem cells are also anticipated to be one of the most expensive treatment options. The high cost arises from the labor-intensive and time-consuming certified process to prepare genetically engineered cells. The surface modification methods discussed earlier have the potential to be applied as an alternative technology to genetic engineering and are more economical with rapid preparation of therapeutic cells.

\section{Application of hydrophobic insertion for cardiac diseases}

\section{Stem cell delivery for cardiac injury}

Cardiac injuries and diseases remain the most common cause of death globally with a higher annual death rate compared to any other causes [101]. The major reason of the highest mortality is that cardiac injury and diseases can progress rapidly, as seen in the cases of acute myocardial infarction (AMI) and MI. Conversely, these cardiac diseases often show lagging progress of cardiac remodeling that frustrates the recovery. Consequently, cardiac hypertrophy and myocardial fibrosis eventually prevail [102-106]. Heart failure and even death may result as a series of catastrophic processes, including cellular injury, mechanical dysfunction, and disruption of structural integrity, occur. Therefore, clinicians and scientists are burdened to develop therapeutic methods to repair and replace the injured cardiomyocytes or associated cells in the infarcted myocardium.

In terms of therapy designed for cardiac injuries and diseases, the treatment options to heal the infarcted cardiac tissue are extremely limited. Currently available therapies for AMI and MI, such as the treatments concentrated on reducing myocardial oxygen needs, extend survival by protecting the remaining cardiomyocytes without addressing the fundamental problem-the loss of cardiomyocytes [107, 108]. Several strategies of cardiac regeneration have emerged from decades of intensive research efforts. Although most of these strategies are still in the early stage, some are beginning to be clinically tested for practicality [109].

Current research in the field of cardiac diseases attempts to stimulate the endogenous regenerative mechanisms via cell-based therapies. Many have believed that regenerative therapies employing stem cells, especially MSCs, have enormous potential for clinical applications to treat cardiac diseases [110]. MSCs, being multipotent stem cells, can differentiate into several cell types, such as mesodermal lineage cells and myogenic lineage [111]. These MSC-based therapies for cardiac diseases are achieved by the intermingling of two major components: a cardiomyocyte source as a target for cardiac regeneration; and a non-myocardial tissue acting as a source for regeneration in an effective cardiac environment [112]. Besides the two major components, other influential factors, such as the type of stem cell being used, its proliferative and differentiation capacity, the targeting to localize the damaged site, the route and site of stem cell transplantation, survival capability of the engrafted cells and so forth, should be carefully tweaked to achieve a successful MSC-based therapy [112].

Regenerative medicine for heart diseases using stem cells has been controversial and readers' discretion is strongly advised [113-115]. One of the most challenged idea is the existence of resident endogenous stem cells or cardiac progenitor cells (CPCs). The current views concur on the fact that $\mathrm{c}-\mathrm{Kit}^{+} \mathrm{CPCs}$, once thought to show regenerative functions and ability to replace the lost cardiomyocytes due to the cardiac injury through differentiating into cardiomyocytes, are rare and have minimal cardiomyogenic potential [116]. However, the prevailing view on the rarity of resident endogenous stem cells should not discourage the idea of stem cell therapy towards cardiac injury and diseases since several preclinical have shown improved cardiac function after the transplantation of MSCs into infarcted heart and clinical studies have reported modest benefits for 
patients with ischemic cardiomyopathy [117-120] Evidence suggests that these beneficial recovery and protective effects are indirect contributions of MSCs through paracrine signaling $[114,121,122]$. The transplanted MSCs secrete growth factors, microRNA (miRNAs), immunomodulatory signals, and exosomes in order to promote prosurvival mechanism and encourage restorative effects in the injured myocardium $[112,114]$. Although clinical results and mechanism of actions have not been clearly shown, it is difficult to preclude the therapeutic benefits of stem cell delivery for heart diseases due to lack of understanding. To reiterate, the ability of any treatment strategies to compensate for the loss of the functioning cardiomyocytes, even though it may not indicate the physical replacement of cardiomyocytes, is the essence of stem cell therapy for cardiac injury. One way to improve the clinical outcome of stem cell therapy is to develop a competent delivery method that can specifically target the disease site within the therapeutic time window. In this aspect, cell surface engineering offers the means to enhance the targeting effect of MSCs, or any discovered therapeutic cells or stem cells, without altering their native functions.

\section{SDF-1/CXCR4 on MSCs}

At the ischemic sites, MSCs can secrete arteriogenic cytokines, such as vascular endothelial growth factor (VEGF), basic fibroblast growth factor (bFGF), placental growth factor (PIGF), and monocyte chemoattractant protein-1 (MCP-1), to repair the damaged tissues $[123,124]$. Thus, many have strived to design a method that allows intravenously infused MSCs to target the injured myocardium. Unfortunately, a negligible number of MSCs migrated to the ischemic myocardium when a large amount of MSCs were intravenously infused [11]. Poor migration of MSCs is related to the loss of CXCR4 expression [125]. Ex vivo expansion of MSCs is necessary to generate a therapeutically relevant number of cells; however, MSCs express heterogeneous CXCR4 with significantly reduced affinity to their corresponding ligands, SDF-1, during the expansion. Moreover, Rombouts et al. have reported that ex vivo expansion of MSCs results in the loss of CXCR4 expression on MSCs [126]. This effect ultimately reduces the chemotaxis of MSCs along the chemokine gradient to specific sites. Systematic administration of MSCs should therefore be improved with a reliable targeting method to enhance therapeutic efficacy.

Immediately after myocardial infarction, injured cardiomyocytes up-regulate SDF-1 expression to recruit stem cells for repair $[127,128]$. Although many studies have stated that migration of $\mathrm{CXCR} 4^{+}$bone marrow stem cells along the SDF-1 concentration gradient is critical for cardiac recovery [127, 129, 130], it has been suggested that the responsiveness to SDF-1 in these cells may mature over 4-7 days after MI [131, 132]. Conversely, expression of SDF-1 in the heart starts to decline 4-7 days after the ischemic injury [127]. Thus, expanding autologous MSCs-which takes several weeks-for the treatment of MI is not ideal due to the shallow therapeutic window of SDF-1 expression.

Previously, CXCR4 expression on MSCs had been induced by hypoxic culture conditions, addition of cytokine cocktails, and viral gene transduction. However, these methods are now discouraged due to the lengthy generation time and risk of altering the MSC properties [12, 133-135]. In order to exploit the SDF-1 gradient for targeted delivery of MSCs to the MI site, pre-expanded MSCs should be rapidly modified with the targeting moiety. Cell surface engineering using the hydrophobic insertions provides an excellent solution to enhance the homing of MSCs to the injured myocardium. Because it noninvasively engineers cells and readily modifies the cell membrane with therapeutic molecules containing lipophilic anchors [136], cell modification by hydrophobic insertion allows instantaneous generation of specialized therapeutic MSCs without a detrimental effect. To demonstrate the feasibility, MSCs were surface-engineered with recombinant CXCR4 (rCXCR4) hydrophobized with DMPE-PEGs (Fig. 2) [43]. In less than $10 \mathrm{~min}$ of incubating pre-expanded MSCs with rCXCR4-PEG-DMPE, specialized MSCs were generated. These cells exhibited a recovered response to SDF-1 with a two-fold improvement of migration ability toward the concentration gradient of SDF-1. Thus, cell surface engineering of MSCs with rCXCR4-PEG-DMPE will be explored with a focus on approaches that further enhance the therapeutic potential of MSCs for regenerative medicine.

\section{Conclusion}

Cell therapy has advanced to the point where it aims to provide treatments for tissue degeneration, chronic inflammation, autoimmunity, genetic disorders, cancer, and infectious diseases [84]. Because the efficacy of cell therapy heavily depends on manipulating the fate and function of therapeutic cells, innovative strategies are continuously being introduced to enhance cell survival, boost native behaviors, add new functions, and improve therapeutic effects. Genetic modification has the advantage of expressing heterologous proteins in cells; however, the expression of desired protein heavily depends on the amount of genetic materials internalized by the cells and the efficiency of protein synthesis of the targeted cells. Nonetheless, viral gene transfer limits the application of genetically modified cells for therapies due to safety and economical concerns, including the use of viral vectors, expensive production cost, and 


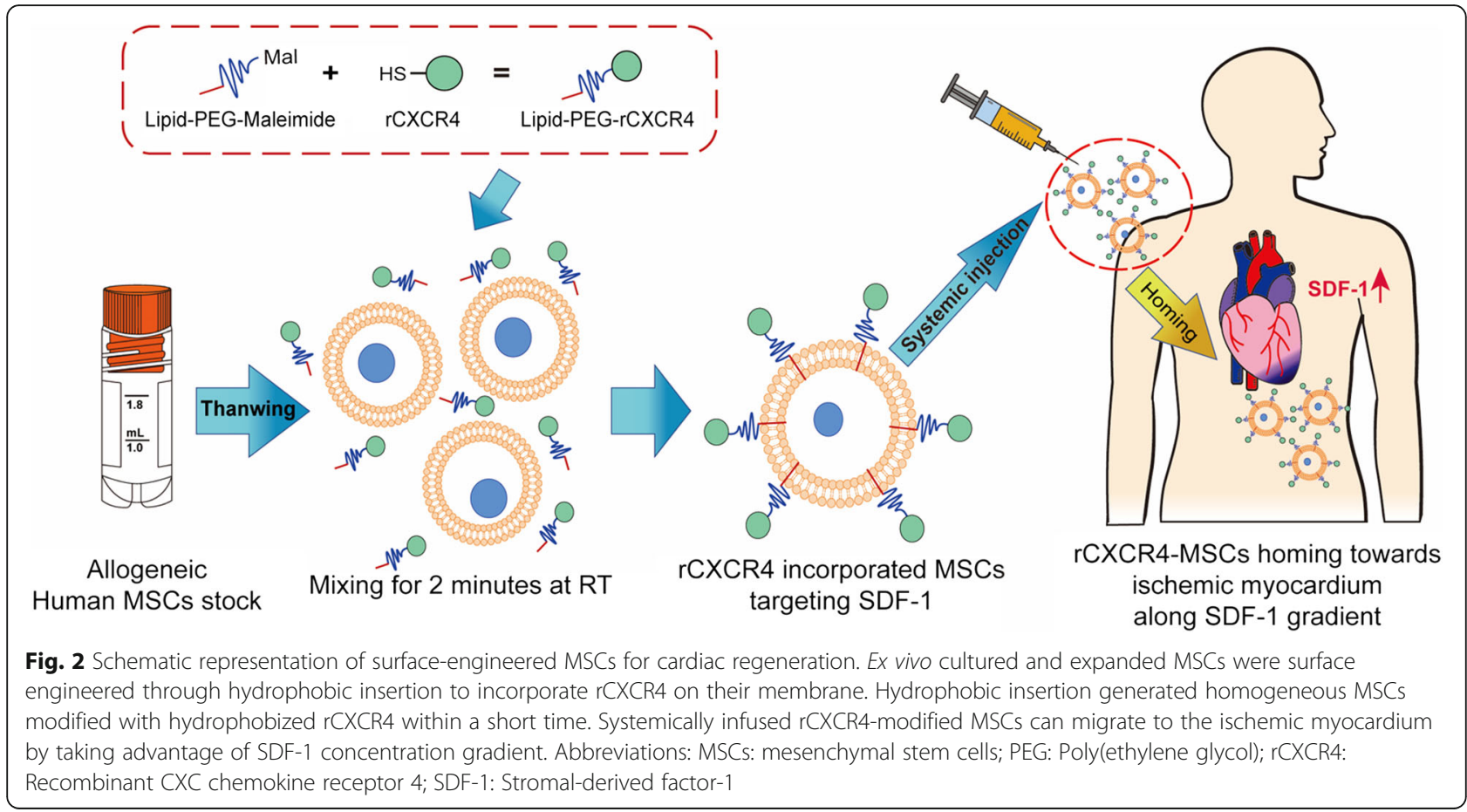

extensive generation time. Non-genetic engineering allows for more creative designs to redirect cells for therapeutic purposes. Both synthetic and natural biomaterials can be incorporated onto the cell surface through covalent conjugation, electrostatic interaction, and hydrophobic interaction in order to provide unique properties and functionalities to cells. Although covalent conjugation and electrostatic interaction provide stable surface modification, the degree of modification is difficult to control. Excessive modification may disrupt the membrane integrity, resulting in severe cytotoxicity. Compared to other surface engineering methods, hydrophobic interaction is a safer membrane modification method that noninvasively modifies the cell surface by inserting lipid-conjugated molecules into the membrane. Despite limited understanding of the fate of lipid conjugated bioactive substances, surface engineering with hydrophobic interaction is an attractive technique because it can be applied to virtually any cell. Non-genetic cell surface engineering to improve their therapeutic potentials is still in its infancy, suggesting each technology should be further tailored to overcome the disadvantage and meet the specific demands of clinical application.

\section{Abbreviations}

AMl: Acute myocardial infarction; BCP-ALL: B cell precursor acute lymphoblastic leukemia; bFGF: Basic fibroblast growth factor; CARs: Chimeric antigen receptors; CD19: Cluster of differentiation 19; CXCR4: CXC chemokine receptor 4; DiD: 1,1'-dioctadecyl-3,3,3',3'- tetramethylindodicarbocyanine, 4chlorobenzenesulfonate salt; Dil: (1,1'-dioctadecyl-3,3,3' ,3'-

tetramethylindocarbocyanine perchlorate); $\mathrm{DiO}: 3,3^{\prime}$

-dioctadecyloxacarbocyanine, perchlorate; DiR: 1,1'-dioctadecyltetramethyl indotricarbocyanine lodide; DMPE: 1,2-dimyristoyl-sn-glycerol-3- phosphatidylethanolamine; DPPE: 1,2-dipalmitoyl-sn-glycerol-3phosphatidylethanolamine; DSPE: 1,2-distearoyl-sn-glycerol-3phosphatidylethanolamine; FDA: Food and Drug Administration; FGF2: Fibroblast growth factor-2; FITC: Fluorescein isothiocyanate; FRAP: Fluorescent recovery after photobleaching; GVHD: Graft-versus-host disease; HA: Hyaluronic acid; HO-1: Heme oxygenase-1; HSCs: Hematopoietic stem cells; IL: Interleukin; iPSCs: Induced pluripotent stem cells; ManNAz: N-aazidoacetylmannosamine; MCP-1: Monocyte chemoattractant protein-1; MHC: Major histocompatibility complex; MI: Myocardial infarction;

MSCs: Mesenchymal stem cells; NHS: N-hydroxyl-succinimidyl ester; NK cells: Natural Killer cells; PAA: Poly(acrylic acid); PAH: Poly(allylamine hydrochloride); PDADMAC or PDDA: Poly(diallydimethylammonium) chloride; PEG: Poly(ethylene glycol); PEI: Poly(ethyleneimine); PIGF: Placental growth factor (PIGF); PLL: Poly-L-lysine; PLL-g-PEG: PLL-graft-poly(ethylene glycol); PPP: Polyphosphoric acid; PSS: Poly(styrene) sulfate; PVA: Poly(vinyl alcohol); rCXCR4: Recombinant CXC chemokine receptor 4; SDF-1: Stromal-derived factor-1; SiaNAz: N-a-azidoacetyl sialic acid; SPR: Surface plasmon resonance; TILs: Tumor infiltrating lymphocytes; VEGF: Vascular endothelial growth factor

\section{Acknowledgements}

Not applicable.

\section{Funding}

This publication was supported by National Heart, Lung, and Blood Institute of the National Institutes of Health under award number R01HL138242.

\section{Availability of data and materials}

Data sharing not applicable to this article as no datasets were generated or analyzed during the current study.

\section{Authors' contributions}

Y-WW and DYL designed this review. DYL primarily wrote the draft and BHC, MJ, and ASK wrote parts of the draft. Y-WW, DYL, BHC, MJ, ASK, and DAB revised the draft and prepared the manuscript. All authors read and approved the final manuscript.

Ethics approval and consent to participate Not applicable. 


\section{Consent for publication}

Not applicable.

\section{Competing interests}

The authors declare that they have no competing interests.

\section{Publisher's Note}

Springer Nature remains neutral with regard to jurisdictional claims in published maps and institutional affiliations.

\section{Received: 26 September 2018 Accepted: 22 November 2018} Published online: 04 December 2018

\section{References}

1. Han J, Park J, Kim BS. Integration of mesenchymal stem cells with nanobiomaterials for the repair of myocardial infarction. Adv Drug Deliv Rev. 2015:95:15-28.

2. Lindvall O, Kokaia Z. Stem cells for the treatment of neurological disorders Nature. 2006;441(7097):1094-6.

3. Marfia G, Navone SE, Di Vito C, Ughi N, Tabano S, Miozzo M, Tremolada C, Bolla G, Crotti C, Ingegnoli F, et al. Mesenchymal stem cells: potential for therapy and treatment of chronic non-healing skin wounds. Organogenesis. 2015;11(4):183-206.

4. Murphy KC, Whitehead J, Falahee PC, Zhou D, Simon SI, Leach JK. Multifactorial Experimental Design to Optimize the Anti-Inflammatory and Proangiogenic Potential of Mesenchymal Stem Cell Spheroids. Stem Cells. 2017;35(6):1493-504

5. Park J, Andrade B, Seo Y, Kim MJ, Zimmerman SC, Kong H. Engineering the Surface of Therapeutic "Living" Cells. Chem Rev. 2018;118(4):1664-90.

6. Segers VF, Lee RT. Stem-cell therapy for cardiac disease. Nature. 2008; 451(7181):937-42.

7. Strauer BE, Brehm M, Zeus T, Kostering M, Hernandez A, Sorg RV, Kogler G, Wernet $P$. Repair of infarcted myocardium by autologous intracoronary mononuclear bone marrow cell transplantation in humans. Circulation. 2002;106(15):1913-8.

8. Rosenberg SA, Restifo NP, Yang JC, Morgan RA, Dudley ME. Adoptive cell transfer: a clinical path to effective cancer immunotherapy. Nature reviews Cancer. 2008:8(4):299-308.

9. Rosenberg SA, Restifo NP. Adoptive cell transfer as personalized immunotherapy for human cancer. Science. 2015;348(6230):62-8.

10. Toma C, Pittenger MF, Cahill KS, Byrne BJ, Kessler PD. Human mesenchymal stem cells differentiate to a cardiomyocyte phenotype in the adult murine heart. Circulation. 2002;105(1):93-8.

11. Barbash IM, Chouraqui P, Baron J, Feinberg MS, Etzion S, Tessone A, Miller L, Guetta E, Zipori D, Kedes LH, et al. Systemic delivery of bone marrowderived mesenchymal stem cells to the infarcted myocardium: feasibility, cell migration, and body distribution. Circulation. 2003:108(7):863-8.

12. Cheng Z, Ou L, Zhou X, Li F, Jia X, Zhang Y, Liu X, Li Y, Ward CA, Melo LG, Kong D. Targeted migration of mesenchymal stem cells modified with CXCR4 gene to infarcted myocardium improves cardiac performance. Mol Ther. 2008;16(3):571-9.

13. Yee C. Adoptive T cell therapy: Addressing challenges in cancer immunotherapy. J Transl Med. 2005;3(1):17.

14. Barrett DM, Grupp SA, June CH. Chimeric Antigen Receptor- and TCRModified T Cells Enter Main Street and Wall Street. J Immunol. 2015;195(3): 755-61.

15. Redeker A, Arens R. Improving Adoptive T Cell Therapy: The Particular Role of T Cell Costimulation, Cytokines, and Post-Transfer Vaccination. Front Immunol. 2016;7:345

16. Yu SP, Wei Z, Wei L. Preconditioning strategy in stem cell transplantation therapy. Transl Stroke Res. 2013;4(1):76-88

17. Hu X, Yu SP, Fraser JL, Lu Z, Ogle ME, Wang JA, Wei L. Transplantation of hypoxia-preconditioned mesenchymal stem cells improves infarcted heart function via enhanced survival of implanted cells and angiogenesis. J Thorac Cardiovasc Surg. 2008:135(4):799-808.

18. Sart S, Ma T, Li Y. Preconditioning stem cells for in vivo delivery. Biores Open Access. 2014;3(4):137-49.

19. Granzin M, Wagner J, Kohl U, Cerwenka A, Huppert V, Ullrich E. Shaping of Natural Killer Cell Antitumor Activity by Ex Vivo Cultivation. Front Immunol. 2017;8:458.
20. Zheng PP, Kros JM, Li J. Approved CAR T cell therapies: ice bucket challenges on glaring safety risks and long-term impacts. Drug Discov Today. 2018;23(6):1175-82.

21. Hodgkinson CP, Gomez JA, Mirotsou M, Dzau VJ. Genetic engineering of mesenchymal stem cells and its application in human disease therapy. Human gene therapy. 2010;21(11):1513-26.

22. Nowakowski A, Walczak P, Lukomska B, Janowski M. Genetic Engineering of Mesenchymal Stem Cells to Induce Their Migration and Survival. Stem Cells Int. 2016;2016:4956063.

23. Kershaw MH, Westwood JA, Darcy PK. Gene-engineered T cells for cancer therapy. Nat Rev Cancer. 2013;13(8):525-41.

24. Tey SK. Adoptive T-cell therapy: adverse events and safety switches. Clin Transl Immunology. 2014;3(6):e17.

25. Glienke W, Esser R, Priesner C, Suerth JD, Schambach A, Wels WS, Grez M, Kloess S, Arseniev L, Koehl U. Advantages and applications of CARexpressing natural killer cells. Front Pharmacol. 2015;6:21.

26. Nowakowski A, Andrzejewska A, Janowski M, Walczak P, Lukomska B. Genetic engineering of stem cells for enhanced therapy. Acta Neurobiol Exp (Wars). 2013;73(1):1-18.

27. Nayak S, Herzog RW. Progress and prospects: immune responses to viral vectors. Gene Ther. 2010;17(3):295-304.

28. Bonifant $\mathrm{CL}$, Jackson HJ, Brentjens RJ, Curran KJ. Toxicity and management in CAR T-cell therapy. Mol Ther Oncolytics. 2016;3:16011.

29. Csizmar CM, Petersburg JR, Wagner CR. Programming Cell-Cell Interactions through Non-genetic Membrane Engineering. Cell Chem Biol. 2018;25(8): 931-40.

30. Nayerossadat N, Maedeh T, Ali PA. Viral and nonviral delivery systems for gene delivery. Adv Biomed Res. 2012;1:27.

31. Contreras JL, Xie D, Mays J, Smyth CA, Eckstein C, Rahemtulla FG, Young CJ, Anthony Thompson J, Bilbao G, Curiel DT, Eckhoff DE. A novel approach to xenotransplantation combining surface engineering and genetic modification of isolated adult porcine islets. Surgery. 2004;136(3):537-47.

32. Stabler CL, Sun XL, Cui W, Wilson JT, Haller CA, Chaikof EL. Surface reengineering of pancreatic islets with recombinant azido-thrombomodulin. Bioconjug Chem. 2007;18(6):1713-5

33. Cabric S, Sanchez J, Lundgren T, Foss A, Felldin M, Kallen R, Salmela K, Tibell A, Tufveson G, Larsson $R$, et al. Islet surface heparinization prevents the instant blood-mediated inflammatory reaction in islet transplantation. Diabetes. 2007:56(8):2008-15.

34. Yun Lee D, Hee Nam J, Byun Y. Functional and histological evaluation of transplanted pancreatic islets immunoprotected by PEGylation and cyclosporine for 1 year. Biomaterials. 2007;28(11):1957-66.

35. Germain M, Balaguer P, Nicolas JC, Lopez F, Esteve JP, Sukhorukov GB, Winterhalter M, Richard-Foy H, Fournier D. Protection of mammalian cell used in biosensors by coating with a polyelectrolyte shell. Biosens Bioelectron. 2006;21(8):1566-73.

36. Elbert DL, Herbert CB, Hubbell JA. Thin polymer layers formed by polyelectrolyte multilayer techniques on biological surfaces. Langmuir. 1999; 15(16):5355-62.

37. Krol S, del Guerra S, Grupillo M, Diaspro A, Gliozzi A, Marchetti P. Multilayer nanoencapsulation. New approach for immune protection of human pancreatic islets. Nano Lett. 2006;6(9):1933-9.

38. Rabuka D, Forstner MB, Groves JT, Bertozzi CR. Noncovalent cell surface engineering: incorporation of bioactive synthetic glycopolymers into cellular membranes. J Am Chem Soc. 2008;130(18):5947-53.

39. Teramura $Y$, Kaneda $Y$, Iwata H. Islet-encapsulation in ultra-thin layer-by-layer membranes of poly(vinyl alcohol) anchored to poly(ethylene glycol)-lipids in the cell membrane. Biomaterials. 2007;28(32):4818-25.

40. Teramura Y, Kaneda Y, Totani T, Iwata H. Behavior of synthetic polymers immobilized on a cell membrane. Biomaterials. 2008:29(10):1345-55.

41. Totani T, Teramura Y, Iwata H. Immobilization of urokinase on the islet surface by amphiphilic poly(vinyl alcohol) that carries alkyl side chains. Biomaterials. 2008;29(19):2878-83

42. Tomita U, Yamaguchi S, Sugimoto Y, Takamori S, Nagamune T. Poly(ethylene glycol)-Lipid-Conjugated Antibodies Enhance Dendritic Cell Phagocytosis of Apoptotic Cancer Cells. Pharmaceuticals (Basel). 2012;5(5):405-16.

43. Won YW, Patel AN, Bull DA. Cell surface engineering to enhance mesenchymal stem cell migration toward an SDF-1 gradient. Biomaterials. 2014;35(21):5627-35.

44. Teramura $Y$, Iwata $H$. Cell surface modification with polymers for biomedical studies. Soft Matter. 2010;6(6):1081-91. 
45. Abbina S, Siren EMJ, Moon H, Kizhakkedathu JN. Surface Engineering for Cell-Based Therapies: Techniques for Manipulating Mammalian Cell Surfaces. ACS Biomat Sci Eng. 2017.

46. Zhao WA, Teo GSL, Kumar N, Karp JM. Chemistry and material science at the cell surface. Mater Today. 2010;13(4):14-21.

47. Carlsten M, Childs RW. Genetic Manipulation of NK Cells for Cancer Immunotherapy: Techniques and Clinical Implications. Front Immunol. 2015;6:266.

48. Lee DY, Lee S, Nam JH, Byun Y. Minimization of immunosuppressive therapy after islet transplantation: combined action of heme oxygenase-1 and PEGylation to islet. Am J Transplant. 2006;6(8):1820-8.

49. Saxon E, Bertozzi CR. Cell surface engineering by a modified Staudinger reaction. Science. 2000;287(5460):2007-10.

50. Prescher JA, Dube DH, Bertozzi CR. Chemical remodelling of cell surfaces in living animals. Nature. 2004:430(7002):873-7.

51. Huang B, Abraham WD, Zheng Y, Bustamante Lopez SC, Luo SS, Irvine DJ. Active targeting of chemotherapy to disseminated tumors using nanoparticle-carrying T cells. Sci Transl Med. 2015;7(291):291ra294.

52. Digilio G, Menchise V, Gianolio E, Catanzaro V, Carrera C, Napolitano R, Fedeli F, Aime S. Exofacial protein thiols as a route for the internalization of Gd(III)-based complexes for magnetic resonance imaging cell labeling. J Med Chem. 2010;53(13):4877-90

53. Torres AG, Gait MJ. Exploiting cell surface thiols to enhance cellular uptake. Trends Biotechnol. 2012;30(4):185-90.

54. Hong V, Steinmetz NF, Manchester M, Finn MG. Labeling live cells by copper-catalyzed alkyne--azide click chemistry. Bioconjug Chem. 2010; 21(10):1912-6.

55. Baskin JM, Prescher JA, Laughlin ST, Agard NJ, Chang PV, Miller IA, Lo A, Codelli JA, Bertozzi CR. Copper-free click chemistry for dynamic in vivo imaging. Proc Natl Acad Sci U S A. 2007;104(43):16793-7.

56. Swee LK, Lourido S, Bell GW, Ingram JR, Ploegh HL. One-step enzymatic modification of the cell surface redirects cellular cytotoxicity and parasite tropism. ACS Chem Biol. 2015;10(2):460-5

57. Paulick MG, Forstner MB, Groves JT, Bertozzi CR. A chemical approach to unraveling the biological function of the glycosylphosphatidylinositol anchor. Proc Natl Acad Sci U S A. 2007;104(51):20332-7.

58. Chanana M, Gliozzi A, Diaspro A, Chodnevskaja I, Huewel S, Moskalenko V, Ulrichs K, Galla HJ, Krol S. Interaction of polyelectrolytes and their composites with living cells. Nano Lett. 2005;5(12):2605-12.

59. Wilson JT, Cui W, Chaikof EL. Layer-by-layer assembly of a conformal nanothin PEG coating for intraportal islet transplantation. Nano Lett. 2008; 8(7):1940-8.

60. Martinez JS, Keller TC 3rd, Schlenoff JB. Cytotoxicity of free versus multilayered polyelectrolytes. Biomacromolecules. 2011;12(11):4063-70.

61. Veerabadran NG, Goli PL, Stewart-Clark SS, Lvov YM, Mills DK Nanoencapsulation of stem cells within polyelectrolyte multilayer shells. Macromol Biosci. 2007;7(7):877-82.

62. Westman EH, Ek M, Enarsson LE, Wagberg L. Assessment of antibacterial properties of polyvinylamine (PVAm) with different charge densities and hydrophobic modifications. Biomacromolecules. 2009;10(6):1478-83.

63. Lv H, Zhang S, Wang B, Cui S, Yan J. Toxicity of cationic lipids and cationic polymers in gene delivery. J Control Release. 2006;114(1):100-9.

64. Wilson JT, Krishnamurthy VR, Cui W, Qu Z, Chaikof EL. Noncovalent cell surface engineering with cationic graft copolymers. J Am Chem Soc. 2009; 131(51):18228-9.

65. Miura S, Teramura Y, Iwata H. Encapsulation of islets with ultra-thin polyion complex membrane through poly(ethylene glycol)-phospholipids anchored to cell membrane. Biomaterials. 2006;27(34):5828-35.

66. Fujita E, Teramura Y, Shiraga T, Yoshioka S, Iwatsubo T, Kawamura A, Kamimura H. Pharmacokinetics and tissue distribution of tacrolimus (FK506) after a single or repeated ocular instillation in rabbits. J Ocul Pharmacol Ther. 2008:24(3):309-19.

67. Agudelo CA, Teramura Y, Iwata H. Cryopreserved agarose-encapsulated islets as bioartificial pancreas: a feasibility study. Transplantation. 2009;87(1):29-34

68. Arima Y, Teramura Y, Takiguchi H, Kawano K, Kotera H, Iwata H. Surface plasmon resonance and surface plasmon field-enhanced fluorescence spectroscopy for sensitive detection of tumor markers. Methods Mol Biol. 2009:503:3-20.

69. Lim KS, Lee DY, Valencia GM, Won YW, Bull DA. Cell surface-engineering to embed targeting ligands or tracking agents on the cell membrane. Biochem Biophys Res Commun. 2017;482(4):1042-7.
70. Itagaki T, Arima Y, Kuwabara R, Kitamura N, Iwata H. Interaction between cells and poly(ethylene glycol)-lipid conjugates. Colloids Surf B Biointerfaces. 2015;135:765-73.

71. Yamamoto T, Teramura $Y$, Itagaki T, Arima $Y$, Iwata H. Interaction of poly(ethylene glycol)-conjugated phospholipids with supported lipid membranes and their influence on protein adsorption. Sci Technol Adv Mater. 2016;17(1):677-84

72. Pulsipher A, Griffin ME, Stone SE, Brown JM, Hsieh-Wilson LC. Directing neuronal signaling through cell-surface glycan engineering. J Am Chem Soc. 2014;136(19):6794-7.

73. Dutta D, Pulsipher A, Luo W, Yousaf MN. Synthetic chemoselective rewiring of cell surfaces: generation of three-dimensional tissue structures. J Am Chem Soc. 2011;133(22):8704-13.

74. Csiszar A, Hersch N, Dieluweit S, Biehl R, Merkel R, Hoffmann B. Novel fusogenic liposomes for fluorescent cell labeling and membrane modification. Bioconjug Chem. 2010;21(3):537-43.

75. Sarkar D, Vemula PK, Zhao W, Gupta A, Karnik R, Karp JM. Engineered mesenchymal stem cells with self-assembled vesicles for systemic cell targeting. Biomaterials. 2010;31(19):5266-74.

76. Inui $\mathrm{O}$, Teramura $\mathrm{Y}$, Iwata $\mathrm{H}$. Retention dynamics of amphiphilic polymers PEG-lipids and PVA-Alkyl on the cell surface. ACS Appl Mater Interfaces. 2010;2(5):1514-20.

77. van Meer G, Voelker DR, Feigenson GW. Membrane lipids: where they are and how they behave. Nat Rev Mol Cell Biol. 2008;9(2):112-24.

78. Sprong H, van der Sluijs $P$, van Meer G. How proteins move lipids and lipids move proteins. Nat Rev Mol Cell Biol. 2001;2(7):504-13.

79. Vellai T, Takacs-Vellai K. Regulation of Protein Turnover by Longevity Pathways. Protein Metabol Homeostasis Aging. 2010;694:69-80.

80. Grant BD, Donaldson JG. Pathways and mechanisms of endocytic recycling. Nat Rev Mol Cell Biol. 2009;10(9):597-608.

81. Adler AF, Leong KW. Emerging links between surface nanotechnology and endocytosis: impact on nonviral gene delivery. Nano Today. 2010; 5(6):553-69

82. McMahon HT, Boucrot E. Molecular mechanism and physiological functions of clathrin-mediated endocytosis. Nat Rev Mol Cell Biol. 2011;12(8):517-33.

83. Kumari S, Mg S, Mayor S. Endocytosis unplugged: multiple ways to enter the cell. Cell Res. 2010;20(3):256-75.

84. Stephan MT, Irvine DJ. Enhancing Cell therapies from the Outside In: Cell Surface Engineering Using Synthetic Nanomaterials. Nano Today. 2011;6(3): 309-25.

85. Ley K, Laudanna C, Cybulsky MI, Nourshargh S. Getting to the site of inflammation: the leukocyte adhesion cascade updated. Nat Rev Immunol. 2007:7(9):678-89.

86. Katritsis D, Kaiktsis L, Chaniotis A, Pantos J, Efstathopoulos EP, Marmarelis V. Wall shear stress: theoretical considerations and methods of measurement. Prog Cardiovasc Dis. 2007;49(5):307-29.

87. Mebius RE, Kraal G. Structure and function of the spleen. Nat Rev Immunol. 2005;5(8):606-16.

88. Dobrovolskaia MA, Aggarwal P, Hall JB, McNeil SE. Preclinical studies to understand nanoparticle interaction with the immune system and its potential effects on nanoparticle biodistribution. Mol Pharm. 2008:5(4):487-95.

89. Nilsson B, Korsgren O, Lambris JD, Ekdahl KN. Can cells and biomaterials in therapeutic medicine be shielded from innate immune recognition? Trends Immunol. 2010;31(1):32-8.

90. Wang JQ, Sui MH, Fan WM. Nanoparticles for Tumor Targeted Therapies and Their Pharmacokinetics. Curr Drug Metab. 2010;11(2):129-41.

91. Dunkelberger JR, Song WC. Complement and its role in innate and adaptive immune responses. Cell Res. 2010;20(1):34-50.

92. Harding FA, Stickler MM, Razo J, DuBridge RB. The immunogenicity of humanized and fully human antibodies: residual immunogenicity resides in the CDR regions. MAbs. 2010;2(3):256-65.

93. Gorbet MB, Sefton MV. Biomaterial-associated thrombosis: roles of coagulation factors, complement, platelets and leukocytes. Biomaterials. 2004;25(26):5681-703.

94. Sperling C, Fischer M, Maitz MF, Werner C. Blood coagulation on biomaterials requires the combination of distinct activation processes. Biomaterials. 2009;30(27):4447-56.

95. Takemoto $\mathrm{N}$, Teramura $\mathrm{Y}$, Iwata $\mathrm{H}$. Islet surface modification with urokinase through DNA hybridization. Bioconjug Chem. 2011;22(4):673-8.

96. Lingwood D, Simons K. Lipid rafts as a membrane-organizing principle. Science. 2010;327(5961):46-50. 
97. Lautenschlager F, Paschke S, Schinkinger S, Bruel A, Beil M, Guck J. The regulatory role of cell mechanics for migration of differentiating myeloid cells. Proc Natl Acad Sci U S A. 2009;106(37):15696-701.

98. Novo C, Fonseca E, Freitas AA. Altered fatty acid membrane composition modifies Iymphocyte localization in vivo. Cell Immunol. 1987;106(2):387-96.

99. Curtis AS, Chandler C, Picton N. Cell surface lipids and adhesion. III. The effects on cell adhesion of changes in plasmalemmal lipids. J Cell Sci. 1975; 18(3):375-84.

100. Klingemann H, Boissel L, Toneguzzo F. Natural Killer Cells for Immunotherapy - Advantages of the NK-92 Cell Line over Blood NK Cells. Front Immunol. 2016;7:91.

101. Doppler SA, Deutsch MA, Lange R, Krane M. Cardiac regeneration: current therapies-future concepts. J Thorac Dis. 2013;5(5):683-97.

102. Galli A, Lombardi F. Postinfarct Left Ventricular Remodelling: A Prevailing Cause of Heart Failure. Cardiol Res Pract. 2016;2016:2579832.

103. Cohn JN, Ferrari R, Sharpe N. Cardiac remodeling--concepts and clinical implications: a consensus paper from an international forum on cardiac remodeling. Behalf of an International Forum on Cardiac Remodeling. J Am Coll Cardiol. 2000:35(3):569-82.

104. Sutton MG, Sharpe N. Left ventricular remodeling after myocardial infarction: pathophysiology and therapy. Circulation. 2000;101(25):2981-8.

105. Talman $\mathrm{V}$, Ruskoaho $\mathrm{H}$. Cardiac fibrosis in myocardial infarction-from repair and remodeling to regeneration. Cell Tissue Res. 2016;365(3):563-81.

106. Prabhu SD, Frangogiannis NG. The Biological Basis for Cardiac Repair After Myocardial Infarction: From Inflammation to Fibrosis. Circ Res. 2016;119(1): 91-112

107. Jadczyk T, Faulkner A, Madeddu P. Stem cell therapy for cardiovascular disease: the demise of alchemy and rise of pharmacology. Br J Pharmacol. 2013;169(2):247-68.

108. Prat-Vidal C, Galvez-Monton C, Puig-Sanvicens V, Sanchez B, Diaz-Guemes I, Bogonez-Franco P, Perea-Gil I, Casas-Sola A, Roura S, Llucia-Valldeperas A, et al. Online monitoring of myocardial bioprosthesis for cardiac repair. Int J Cardiol. 2014;174(3):654-61.

109. Lin Z, Pu WT. Strategies for cardiac regeneration and repair. Sci Transl Med. 2014;6(239):239rv231.

110. Hare JM, Chaparro SV. Cardiac regeneration and stem cell therapy. Curr Opin Organ Transplant. 2008;13(5):536-42.

111. Short B, Brouard N, Occhiodoro-Scott T, Ramakrishnan A, Simmons PJ. Mesenchymal stem cells. Arch Med Res. 2003;34(6):565-71.

112. Singh A, Singh A, Sen D. Mesenchymal stem cells in cardiac regeneration: a detailed progress report of the last 6 years (2010-2015). Stem Cell Res Ther. 2016;7(1):82.

113. van Berlo JH, Kanisicak O, Maillet M, Vagnozzi RJ, Karch J, Lin SC, Middleton RC, Marban E, Molkentin JD. c-kit+ cells minimally contribute cardiomyocytes to the heart. Nature. 2014;509(7500):337-41.

114. Hashimoto H, Olson EN, Bassel-Duby R. Therapeutic approaches for cardiac regeneration and repair. Nat Rev Cardiol. 2018;15(10):585-600.

115. Cai CL, Molkentin JD. The Elusive Progenitor Cell in Cardiac Regeneration: Slip Slidin' Away. Circ Res. 2017;120(2):400-6.

116. Tzahor E, Poss KD. Cardiac regeneration strategies: Staying young at heart Science. 2017;356(6342):1035-9.

117. Quevedo HC, Hatzistergos KE, Oskouei BN, Feigenbaum GS, Rodriguez JE, Valdes D, Pattany PM, Zambrano JP, Hu Q, McNiece I, et al. Allogeneic mesenchymal stem cells restore cardiac function in chronic ischemic cardiomyopathy via trilineage differentiating capacity. Proc Natl Acad Sci U S A. 2009;106(33):14022-7.

118. Amado LC, Saliaris AP, Schuleri KH, St John M, Xie JS, Cattaneo S, Durand DJ, Fitton T, Kuang JQ, Stewart G, et al. Cardiac repair with intramyocardial injection of allogeneic mesenchymal stem cells after myocardial infarction. Proc Natl Acad Sci U S A. 2005;102(32):11474-9.

119. Hare JM, Fishman JE, Gerstenblith G, DiFede Velazquez DL, Zambrano $J P$, Suncion VY, Tracy M, Ghersin E, Johnston PV, Brinker JA, et al. Comparison of allogeneic vs autologous bone marrow-derived mesenchymal stem cells delivered by transendocardial injection in patients with ischemic cardiomyopathy: the POSEIDON randomized trial. JAMA. 2012;308(22):2369-79.

120. Mathiasen AB, Qayyum AA, Jorgensen E, Helqvist S, Fischer-Nielsen A, Kofoed KF, Haack-Sorensen M, Ekblond A, Kastrup J. Bone marrow-derived mesenchymal stromal cell treatment in patients with severe ischaemic heart failure: a randomized placebo-controlled trial (MSC-HF trial). Eur Heart J. 2015;36(27):1744-53
121. Roura S, Galvez-Monton C, Mirabel C, Vives J, Bayes-Genis A. Mesenchymal stem cells for cardiac repair: are the actors ready for the clinical scenario? Stem Cell Res Ther. 2017;8(1):238.

122. Chen TS, Lai RC, Lee MM, Choo AB, Lee CN, Lim SK. Mesenchymal stem cell secretes microparticles enriched in pre-microRNAs. Nucleic Acids Res. 2010; 38(1):215-24.

123. Kinnaird T, Stabile E, Burnett MS, Shou M, Lee CW, Barr S, Fuchs S, Epstein SE. Local delivery of marrow-derived stromal cells augments collateral perfusion through paracrine mechanisms. Circulation. 2004;109(12):1543-9.

124. Kinnaird T, Stabile E, Burnett MS, Lee CW, Barr S, Fuchs S, Epstein SE. Marrow-derived stromal cells express genes encoding a broad spectrum of arteriogenic cytokines and promote in vitro and in vivo arteriogenesis through paracrine mechanisms. Circ Res. 2004;94(5):678-85.

125. Wynn RF, Hart CA, Corradi-Perini C, O'Neill L, Evans CA, Wraith JE, Fairbairn LJ, Bellantuono I. A small proportion of mesenchymal stem cells strongly expresses functionally active CXCR4 receptor capable of promoting migration to bone marrow. Blood. 2004;104(9):2643-5.

126. Rombouts WJ, Ploemacher RE. Primary murine MSC show highly efficient homing to the bone marrow but lose homing ability following culture. Leukemia. 2003;17(1):160-70.

127. Askari AT, Unzek S, Popovic ZB, Goldman CK, Forudi F, Kiedrowski M, Rovner A, Ellis SG, Thomas JD, DiCorleto PE, et al. Effect of stromal-cell-derived factor 1 on stem-cell homing and tissue regeneration in ischaemic cardiomyopathy. Lancet. 2003;362(9385):697-703.

128. Abbott JD, Huang Y, Liu D, Hickey R, Krause DS, Giordano FJ. Stromal cellderived factor-1alpha plays a critical role in stem cell recruitment to the heart after myocardial infarction but is not sufficient to induce homing in the absence of injury. Circulation. 2004;110(21):3300-5.

129. Tang YL, Qian K, Zhang YC, Shen L, Phillips MI. Mobilizing of haematopoietic stem cells to ischemic myocardium by plasmid mediated stromal-cell-derived factor-1alpha (SDF-1alpha) treatment. Regul Pept. 2005; 125(1-3):1-8.

130. Misao Y, Takemura G, Arai M, Ohno T, Onogi H, Takahashi T, Minatoguchi S, Fujiwara T, Fujiwara $\mathrm{H}$. Importance of recruitment of bone marrow-derived CXCR4+ cells in post-infarct cardiac repair mediated by G-CSF. Cardiovasc Res. 2006;71(3):455-65.

131. Schachinger V, Erbs S, Elsasser A, Haberbosch W, Hambrecht R, Holschermann H, Yu J, Corti R, Mathey DG, Hamm CW, et al. Intracoronary bone marrow-derived progenitor cells in acute myocardial infarction. $\mathrm{N}$ Engl J Med. 2006;355(12):1210-21.

132. Penn MS. Importance of the SDF-1:CXCR4 axis in myocardial repair. Circ Res. 2009:104(10):1133-5.

133. Ghadge SK, Muhlstedt S, Ozcelik C, Bader M. SDF-1alpha as a therapeutic stem cell homing factor in myocardial infarction. Pharmacol Ther. 2011; 129(1):97-108

134. Shi M, Li J, Liao L, Chen B, Li B, Chen L, Jia H, Zhao RC. Regulation of CXCR4 expression in human mesenchymal stem cells by cytokine treatment: role in homing efficiency in NOD/SCID mice. Haematologica. 2007;92(7):897-904.

135. Liu H, Xue W, Ge G, Luo X, Li Y, Xiang H, Ding X, Tian P, Tian X. Hypoxic preconditioning advances CXCR4 and CXCR7 expression by activating HIF1alpha in MSCs. Biochem Biophys Res Commun. 2010;401(4):509-15.

136. Chung HA, Kato K, Itoh C, Ohhashi S, Nagamune T. Casual cell surface remodeling using biocompatible lipid-poly(ethylene glycol)(n): development of stealth cells and monitoring of cell membrane behavior in serum-supplemented conditions. J Biomed Mater Res A 2004;70(2):179-85.

Ready to submit your research? Choose BMC and benefit from:

- fast, convenient online submission

- thorough peer review by experienced researchers in your field

- rapid publication on acceptance

- support for research data, including large and complex data types

- gold Open Access which fosters wider collaboration and increased citations

- maximum visibility for your research: over $100 \mathrm{M}$ website views per year

At $\mathrm{BMC}$, research is always in progress.

Learn more biomedcentral.com/submission 